OPEN ACCESS

Edited by:

Jichao Zhao,

The University of Auckland,

New Zealand

Reviewed by:

Martin Stiles,

The University of Auckland,

New Zealand

Ghassen Cheniti,

Centre Hospitalier Universitaire ( $\mathrm{CHU}$ )

de Bordeaux, France

*Correspondence:

Anne M. Gillis

amgillis@ucalgary.ca

Specialty section:

This article was submitted to

Computational Physiology and

Medicine,

a section of the journal

Frontiers in Physiology

Received: 30 April 2018 Accepted: 04 February 2019

Published: 26 February 2019

Citation:

Bohne LJ, Johnson D, Rose RA, Wilton SB and Gillis AM (2019) The

Association Between Diabetes Mellitus and Atrial Fibrillation: Clinical

and Mechanistic Insights

Front. Physiol. 10:135

doi: 10.3389/fphys.2019.00135

\section{The Association Between Diabetes Mellitus and Atrial Fibrillation: Clinical and Mechanistic Insights}

\author{
Loryn J. Bohne, Dustin Johnson, Robert A. Rose, Stephen B. Wilton and Anne M. Gillis*
}

Department of Cardiac Sciences and Department of Physiology and Pharmacology, University of Calgary and Libin Cardiovascular Institute of Alberta, Calgary, AB, Canada

A number of clinical studies have reported that diabetes mellitus (DM) is an independent risk factor for Atrial fibrillation (AF). After adjustment for other known risk factors including age, sex, and cardiovascular risk factors, DM remains a significant if modest risk factor for development of AF. The mechanisms underlying the increased susceptibility to AF in DM are incompletely understood, but are thought to involve electrical, structural, and autonomic remodeling in the atria. Electrical remodeling in DM may involve alterations in gap junction function that affect atrial conduction velocity due to changes in expression or localization of connexins. Electrical remodeling can also occur due to changes in atrial action potential morphology in association with changes in ionic currents, such as sodium or potassium currents, that can affect conduction velocity or susceptibility to triggered activity. Structural remodeling in DM results in atrial fibrosis, which can alter conduction patterns and susceptibility to re-entry in the atria. In addition, increases in atrial adipose tissue, especially in Type II DM, can lead to disruptions in atrial conduction velocity or conduction patterns that may affect arrhythmogenesis. Whether the insulin resistance in type II DM activates unique intracellular signaling pathways independent of obesity requires further investigation. In addition, the relationship between incident AF and glycemic control requires further study.

Keywords: atrial fibrillation, diabetes mellitus, risk factors, mechanisms, atrial remodeling

\section{INTRODUCTION}

Atrial fibrillation (AF) is the most common sustained arrhythmia and is associated with substantial morbidity and mortality. Risk factors for atrial fibrillation include age, hypertension, obesity, valvular heart disease, heart failure, and obstructive sleep apnea (Benjamin et al., 1994; Staerk et al., 2017). Some but not all studies have reported that diabetes mellitus (DM) is an independent risk factor for AF (Benjamin et al., 1994; Krahn et al., 1995; Huxley et al., 2011). Here we will review the clinical data supporting the association between DM and AF and discuss the potential mechanism(s) by which DM may contribute to the electrophysiologic substrate for AF. We also suggest future potential research studies to advance our knowledge in this field. 


\section{ASSOCIATION BETWEEN DM AND AF: CLINICAL STUDIES}

A potential association between $\mathrm{DM}$ and incidence of $\mathrm{AF}$ has long been postulated based on epidemiologic studies. The original Framingham Heart Study consisted of 5,209 patients (2,336 men, 2,873 women), age 30-62 years of age. This study initiated in 1948 represented a random sample of two thirds of the population of Framingham, Massachusetts and has conducted pivotal research defining cardiovascular risk factors (Tsao and Vasan, 2015). This study reported that hypertension, diabetes, congestive heart failure and valvular heart disease were independent risk factors for AF in both men and women (Benjamin et al., 1994). The odds ratio (OR) of risk of developing $\mathrm{AF}$ in the association with DM was 1.4 (95\% CI 1.0-2.0) and 1.6 (95\% CI 1.1-2.2) for men and women, respectively. However, in the absence of valvular heart disease, diabetes was no longer a significant risk predictor for the development of AF. The Framingham Heart Study did not include body mass index (BMI) or a history of obstructive sleep apnea in this initial analysis.

The Manitoba Follow-Up Study which also commenced in 1948 prospectively followed 3,983 healthy male air crew recruits for 44 years. The goal of this study was to examine the role that abnormalities on the resting electrocardiogram might play in the prediction of future cardiovascular disease. In this cohort, obesity [relative risk (RR) 1.28; 95\% CI 1.02-1.62] but not $\mathrm{DM}$ was reported to be an independent risk factor for $\mathrm{AF}$ (Krahn et al., 1995).

In 2011, Huxley et al. reported the results of a systematic review and meta-analysis examining the association between DM and AF (Huxley et al., 2011). They identified seven prospective cohort studies and four case control studies that included 108,703 individuals with AF and 1,686,097 control subjects. Overall, DM was associated with a $39 \%$ increased risk of AF compared to controls (RR 1.39, 95\% CI 1.10-1.75). However, only three of these studies reported multivariable adjusted risk estimates for AF (adjusting for age and some other risk factors). Perhaps, not surprisingly, after adjusting for these known factors the association between DM and AF was significantly attenuated and in two of these studies was no longer statistically significant. Thus, the association between DM and incident AF has likely been overestimated in this meta-analysis. Furthermore, these previous studies did not specifically distinguish between Type I or Type II DM, glycemic control or specific therapies.

Since this meta-analysis was published, several additional observational studies examining the association between DM and AF have been reported. The Atherosclerosis Risk in Communities study is comprised of 15,792 white and African American patients age 45-64 years pooled from 4 geographically distinct communities in the United States. A 2012 report from this cohort examined the associations between Type II DM, markers of glucose homeostasis and risk of AF (Huxley et al., 2012). After adjustment for a number of risk factors, DM was associated with a significant increased risk for AF [hazard ratio (HR) 1.35, 95\% CI 1.14-1.60] (Figure 1). However, those with pre diabetes or undiagnosed diabetes were not at increased risk for AF.
The authors also reported a positive linear association between HbA1c and the risk of AF for both those with and without $\mathrm{DM}$, though a similar positive relationship between fasting blood glucose and risk for AF was observed only in patients with previously diagnosed DM (Huxley et al., 2012).

In the Women's Health Study, Type II DM was a significant predictor of risk for AF (HR 1.37; 95\% CI 1.03-1.83) after adjustment for cardiovascular risk factors including hypertension and BMI (Schoen et al., 2012). However, these investigators observed that the development of hypertension, obesity, and cardiovascular disease over time were stronger predictors of risk of incident AF compared to DM. In a subgroup analysis of the Women's Health Study, baseline HbA1c was not predictive of subsequent AF.

Risk factors for AF were evaluated in post-menopausal women in the Women's Health Initiative Observational Study (Perez et al., 2013). Consistent with earlier observational cohort studies, age, hypertension, obesity, diabetes, myocardial infarction, and congestive heart failure were all independently associated with incident AF. However, hypertension and overweight status/obesity contributed to 28.3 and $12.1 \%$ of the population attributable risk for AF whereas DM accounted for only $3.4 \%$ of this risk. A Korean National Health Insurance Service Database analysis confirmed that after adjustment for age, sex, BMI, and other covariates the population attributable risk of $\mathrm{AF}$ for hypertension, ischemic heart disease, heart failure and DM were $16,8.2,5.3$, and $0.8 \%$, respectively (Son et al., 2016). In this latter analysis, DM was not a significant risk predictor for AF.

A Danish Nation cohort study evaluated the risk of AF in individuals with DM compared to the background Danish population (Pallisgaard et al., 2016). After adjustment for multiple covariates, DM was associated with a relative $19 \%$ increased risk of incident AF. Interestingly, the incidence rate ratio was highest in the youngest age group $18-39$ years $(2.34,95 \%$ CI 1.52-3.60) compared to older patients $(1.20,95 \%$ CI $1.18-1.23$ age group 65-74). This analysis did not stratify relative risks for those with Type I vs. Type II DM or describe the duration of DM prior to AF diagnosis, so the apparent effect modification by age is not easily explained. The relative decrease in risk of AF in DM with increasing age may reflect the importance of other risk factors for AF that occur with advancing age.

A recent prospective, case control study examined the relationship between Type I diabetes and AF (Dahlqvist et al., 2017). Using a Swedish database, Dahlqvist compared 36258 patients with Type I DM to 179,980 controls followed for a median of 9.7 years. The mean age of participants was 35 years. Type I DM was associated with a modest increase in the risk of $\mathrm{AF}$ in men (HR 1.13, 95\% CI 1.01-1.25), but a 50\% increase risk of AF in women (HR 1.5, 95\% CI 1.3-1.72). The risk of AF was increased in those with worse glycemic control and renal complications (Figure 2).

In this issue of Frontiers in Physiology (Xiong et al., 2018), have summarized the current state of the literature in an updated systematic review and meta-analysis including 


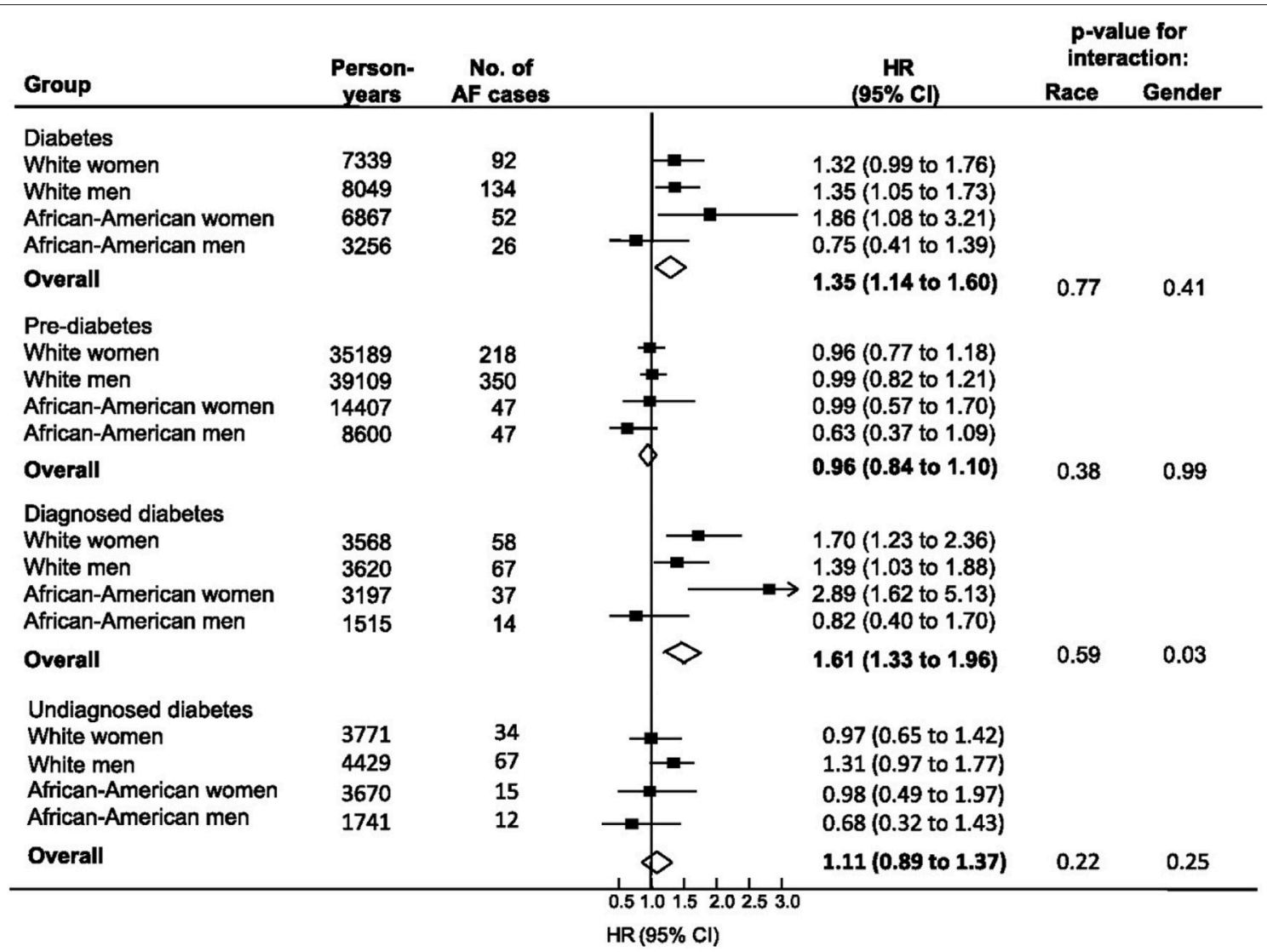

FIGURE 1 | Relationship between diabetes, pre-diabetes, and physician-diagnosed diabetes with incident atrial fibrillation from the ARIC study (1990-2007). Individuals without diabetes comprised the reference group for each comparison. Diabetes included all individuals with $\mathrm{FSG}>126 \mathrm{mg} / \mathrm{dl}$ or $\mathrm{HbA} 1 \mathrm{c}>6.5 \%$ or use of diabetic medication or history of physician-diagnosed diabetes. Undiagnosed diabetes defined as fasting serum glucose (FSG) $>126$ mg/dl or $\mathrm{HbA} 1 \mathrm{C}>6.5 \%$ but no history of diabetic medication usage or physician diagnosed diabetes. Black boxes represent the estimate adjusted for age, education, income, prior history of cardiovascular disease, BMI, systolic blood pressure, use of hypertensive medications, and smoking. Horizontal lines represent 95\% confidence intervals. Open diamonds represent the estimate of effect for the overall population. Note the strong correlation between DM and AF among African American women. Reproduced with permission from Huxley et al. (2012).

publications reported up to September 2017 that investigated the association between DM and AF. They used a novel machine learning approach to identify publications suitable for analysis. Twenty-nine studies (21 observational cohort or randomized trials and 8 case control studies) including 8,037,756 subjects were included in the analysis. Overall DM was associated with a pooled $49 \%$ increased risk of developing AF (RR 1.49, 95\% CI1.24-1.79). However, many studies did not adjust for known risk predictors including age, sex and cardiovascular risk factors. When restricted to studies reporting adjusted estimates, DM was associated with a weaker but still significant increased risk of new onset AF (RR 1.23, $95 \%$ CI 1.03-1.46). Furthermore, there was significant between-study heterogeneity in the observed associations that could not be explained by available differences in baseline covariates, type of DM, or study era. Interestingly, in this study the association between $\mathrm{DM}$ and incident $\mathrm{AF}$ was stronger in women than in men (RR 1.38, 95\% CI 1.191.60 vs. $1.11,95 \%$ CI 1.01-1.22). In addition, the association between $\mathrm{DM}$ and incident $\mathrm{AF}$ was stronger in more recent vs. older studies.
The clinical studies discussed are summarized in Table 1. These clinical studies examining the potential association between DM and AF incidence share important limitations. Most publications are secondary reports from large cohorts assembled for another purpose, without detailed characterization of the type, duration or severity of DM, nor standardized AF detection protocols. Furthermore, there has been variable adjustment for confounding by other risk factors such as obesity, obstructive sleep apnea, and heart failure. This may in part explain the contradictory results.

Notwithstanding these limitations, DM appears to be a significant if modest risk factor for development of AF. This association may be increasing in strength over time, as secular trends in other risk factors especially better control of hypertension and management of heart failure (Schnabel et al., 2015) and an increasing incidence of obesity and DM worldwide have been reported. These changes suggest that more attention to the diagnosis and management of $\mathrm{DM}$ as well as aggressive weight loss interventions for overweight/obese individuals may be important in curbing 


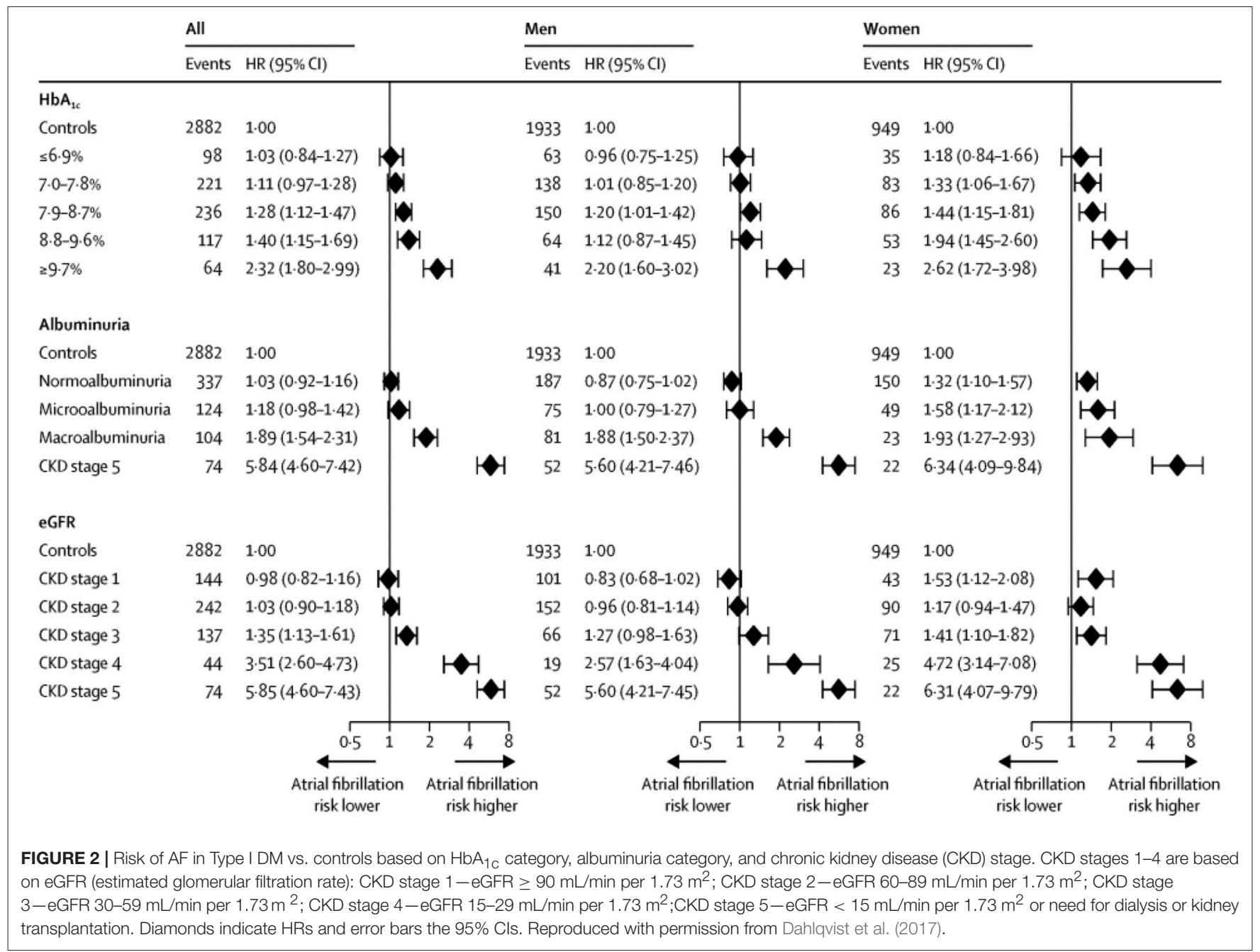

the emerging epidemic of AF. The contradictory results from the available clinical data set also serves to highlight the importance of fundamental research to elucidate the mechanisms by which DM might promote AF, summarized in the next section.

\section{MECHANISMS OF AF IN DM: INSIGHTS FROM EXPERIMENTAL STUDIES}

\section{Mechanisms of Atrial Fibrillation}

While the mechanisms underlying $\mathrm{AF}$ are incompletely understood, research efforts have identified a substantial number of pathophysiological determinants, including at the cellular and molecular levels, that can lead to electrical and structural remodeling and thereby favor the occurrence of AF. These include a number of mechanisms that can lead to triggers for AF initiation as well as mechanisms that create a substrate for AF maintenance and progression (Heijman et al., 2014, 2018). Below, we focus our discussion on alterations that have been shown or proposed to lead to AF specifically in the setting of DM. These potential mechanism(s) are outlined in Figure 3.

\section{Animal Models of Diabetes Mellitus and AF Research}

A number of animal models of DM have been employed to study the atrial electrical and structural changes and the underlying molecular mechanism(s) that predispose to AF in this setting. These include models of Type I DM induced by chemical induction using streptozotocin or alloxan (King, 2012; Watanabe et al., 2012; Liu et al., 2014, 2017; Saito et al., 2014; Fu et al., 2015; Yi et al., 2015; Hayami et al., 2016), which have been successfully employed in rodents and rabbits. The Akita mouse model of Type 1 DM which arose due to a mutation in the insulin-2 gene replicates many of the complications of diabetes including retinopathy, neuropathy, nephropathy and increased oxidative stress (Hsueh et al., 2007). Most current animal models of type II DM are associated with obesity. These include monogenic models of leptin deficiency (mice) or deficiency in the leptin receptor (mice, Zucker fatty rats and diabetic fatty rats (King, 2012; Linz et al., 2016; Fukui et al., 2017). Type II DM induced by high fat feeding has been used in rabbits (Zarzoso et al., 2014). Models of metabolic syndrome characterized by central obesity, hyperlipidemia, glucose intolerance and hypertension have been 
TABLE 1 | Characteristics of Clinical Studies Examining the Relationship Between Diabetes Mellitus and Atrial Fibrillation.

\begin{tabular}{|c|c|c|c|c|}
\hline Authors & Study design & Findings & Limitations & Diabetes type \\
\hline Benjamin et al., 1994 & $\begin{array}{l}\text { Prospective cohort } \\
2,090 \text { men } \\
\text { 2,641 women } \\
\text { Ages 55-94 years }\end{array}$ & $\begin{array}{l}\text { HTN, DM, CHF, VHD } \\
\text { independent risk factors for AF. } \\
\text { DM risk: OR } 1.4 \text { men, } 1.6 \\
\text { women }\end{array}$ & $\begin{array}{l}\text { DM not a risk factor for AF } \\
\text { after controlling for valvular } \\
\text { heart disease. } \\
\text { BMI and OSA not included } \\
\text { in analysis }\end{array}$ & Not specified \\
\hline Krahn et al., 1995 & $\begin{array}{l}\text { Prospective cohort } \\
3,983 \text { men }\end{array}$ & $\begin{array}{l}\text { Abnormalities in resting ECG did } \\
\text { not predict AF. } \\
\text { Obesity but not DM a risk for AF }\end{array}$ & & Not specified \\
\hline Huxley et al., 2011 & $\begin{array}{l}\text { Systematic review and meta-analysis } \\
\text { of } 7 \text { prospective cohort studies, } 4 \\
\text { case control studies. } \\
108,703 \text { with AF } \\
1,686,099 \text { control subjects }\end{array}$ & $\begin{array}{l}39 \% \text { increased risk of } \mathrm{AF} \text { in } \mathrm{DM} \\
\text { compared to controls }\end{array}$ & $\begin{array}{l}\text { Effect significantly } \\
\text { attenuated after } \\
\text { multivariable adjusted risk } \\
\text { estimates }\end{array}$ & Type II DM \\
\hline Huxley et al., 2012 & $\begin{array}{l}\text { Prospective cohort } \\
13,025 \text { subjects }\end{array}$ & $\begin{array}{l}35 \% \text { increased risk of AF in DM } \\
\text { after adjustment for known risk } \\
\text { factors }\end{array}$ & $\begin{array}{l}\text { Cases of AF ascertained } \\
\text { through hospital discharge } \\
\text { codes }\end{array}$ & Type II DM \\
\hline Schoen et al., 2012 & 34,720 female health professionals & $\begin{array}{l}37 \% \text { increased risk of for } A F \text { in } \\
\text { DM. } \\
\text { HTN, CVD, obesity stronger } \\
\text { predictors of AF than DM }\end{array}$ & $\begin{array}{l}\text { Possible under diagnosis of } \\
\text { DM given lack of systemic } \\
\text { screening }\end{array}$ & Type II DM \\
\hline Perez et al., 2013 & $\begin{array}{l}\text { Observational cohort } \\
81,892 \text { post-menopausal women }\end{array}$ & $\begin{array}{l}\text { Age, HTN, obesity, DM, MI, CHF } \\
\text { risk factors for AF. } \\
\text { DM risk: HR } 1.55 \text { in multivariable } \\
\text { analysis }\end{array}$ & $\begin{array}{l}98 \% \text { of incident AF based } \\
\text { on hospital discharge codes }\end{array}$ & Not specified \\
\hline Son et al., 2016 & $\begin{array}{l}\text { Korean National Health Insurance } \\
\text { Data } \\
206,013 \text { subjects age }>30 \text { years }\end{array}$ & Diabetes not a risk factor for AF & $\begin{array}{l}\text { Incident AF based on } \\
\text { disease codes }\end{array}$ & Not specified \\
\hline Pallisgaard et al., 2016 & $\begin{array}{l}\text { Danish National Registries } \\
5,0081,087 \text { subjects }>18 \text { years }\end{array}$ & $\begin{array}{l}19 \% \text { increased risk of AF in DM } \\
\text { IRR } 2.34 \text { age } 18-39 \\
\text { IRR } 1.20 \text { age } 65-74\end{array}$ & $\begin{array}{l}\text { Incident AF based on } \\
\text { disease codes }\end{array}$ & Not specified \\
\hline Xiong et al., 2018 & $\begin{array}{l}\text { Systemic review and meta-analysis } \\
21 \text { observational cohort or } \\
\text { randomized trials and } 8 \text { case control } \\
\text { studies } 8,037,756 \text { subjects }\end{array}$ & $\begin{array}{l}\text { RR for AF in DM } \\
1.38 \text { (women) } \\
1.11 \text { (men) }\end{array}$ & $\begin{array}{l}\text { Significant between study } \\
\text { heterogeneity in observed } \\
\text { associations }\end{array}$ & Majority Type II DM \\
\hline Dahlqvist et al., 2017 & $\begin{array}{l}\text { Prospective case control study } \\
36,258 \text { patients Type I DM } \\
\text { 179,980 control subjects }\end{array}$ & $\begin{array}{l}\text { Modest } 13 \% \text { increased risk of AF } \\
\text { in men Significant } 50 \% \text { increased } \\
\text { risk of AF in women. } \\
\text { Risk greater in those with poor } \\
\text { glycemic control }\end{array}$ & $\begin{array}{l}\text { No data on blood pressure } \\
\text { or BMl }\end{array}$ & Type I DM \\
\hline
\end{tabular}

AF, atrial fibrillation; HTN, hypertension; CHF, congestive heart failure; IRR, incident risk ratio; CVD, cardiovascular disease; OR, odds ratio; DM, diabetes mellitus; RR, relative risk; HR, hazard ratio; VHD, valvular heart disease.

induced using a combination of high fat and high sucrose diets in rodents (Hohl et al., 2017) and rabbits (Arias-Mutis et al., 2017).

\section{Atrial Structural Remodeling}

Diabetes is known to exacerbate interstitial fibrosis in the atria. This is seen in both animal (Kato et al., 2008; Watanabe et al., 2012; Li et al., 2016) and human (Lamberts et al., 2014) studies. Atrial fibrosis has been demonstrated in studies of Type I DM (Kato et al., 2008) and Type II DM (Li et al., 2016). Obesity often leads to Type II DM and is associated with lipomatous metaplasia of the heart, a process that involves the transformation of fatty infiltrates into fibrotic tissue (Samanta et al., 2016). A sheep model of obesity induced by high caloric diet in the absence of DM induces significant atrial structural and electrical remodeling. The changes reported included left atrial enlargement, biatrial conduction abnormalities, increased expression of profibrotic mediators, interstitial atrial fibrosis, and an increased propensity for inducible and spontaneous AF (Abed et al., 2013; Mahajan et al., 2015). Therefore, in the case of Type II $\mathrm{DM}$, it is unclear whether the observed atrial interstitial fibrosis and associated atrial conduction abnormalities are the result of either chronic diabetes or excessive adiposity alone.

\section{Fibrosis}

Fibrosis can be a critical contributor to the establishment of a substrate for AF as increased collagen deposition in the atria can slow atrial conduction velocity and cause fragmentation of propagating wavefronts, which can result in re-entry (Schotten et al., 2016). Fibrosis is importantly determined by the function of cardiac fibroblasts, which play a central role in the deposition 


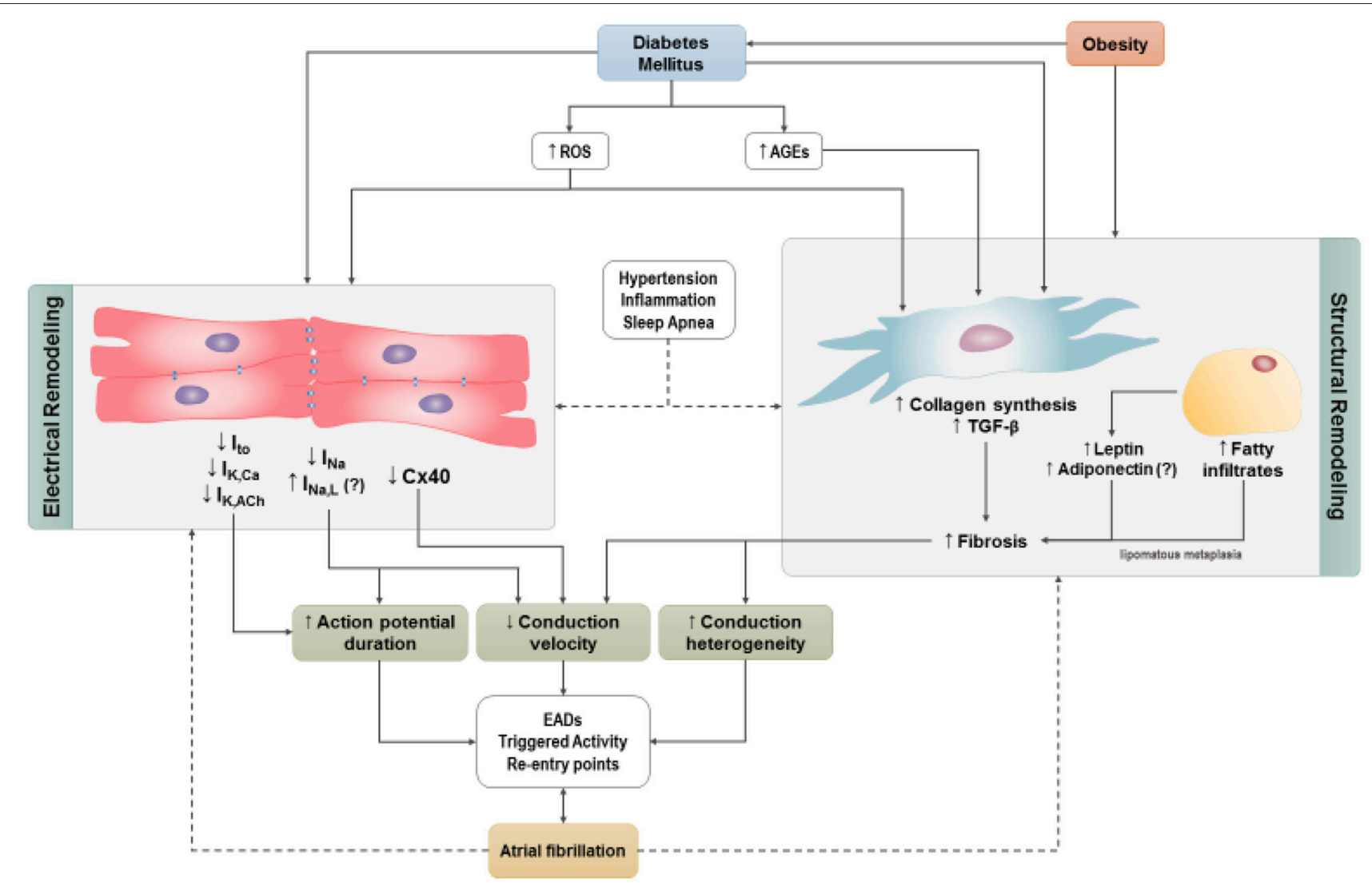

FIGURE 3 | Cellular mechanisms by which diabetes may predispose to AF. Increases in reactive oxygen species and/or advanced glycation-end products trigger atrial electrical and structural remodeling. Obesity independent of DM contributes to atrial structural remodeling. Hypertension, obstructive sleep apnea, and systemic inflammation are frequently associated with DM and contribute to atrial electrical and structural remodeling. ROS, reactive oxygen species; AGE, advanced glycation-end products (AGES); I to , transient outward current; $\mathbb{I}_{\mathrm{Ca}}, \mathrm{Ca}^{2+}$-activated potassium channels; $I_{\mathrm{KACh}}$, Acetylcholine dependent potassium current; $I_{\mathrm{Na}}$, sodium current; INaL, late inward sodium current; TGF- $\beta$, transforming growth factor- $\beta$; EADs, early after depolarizations; Cx40, connexin 40.

of the extracellular matrix. In a number of pathological conditions, fibroblasts are activated leading to inappropriate collagen production and deposition. Cardiac fibrosis has been clearly demonstrated in diabetic patients and, consistent with this, cardiac fibroblasts isolated from the atria of patients with Type II DM show enhanced levels of collagen synthesis, as indicated by increased expression of Type I collagen (Sedgwick et al., 2014). Similar results have been observed in $\mathrm{db} / \mathrm{db}$ mice, in which cultured ventricular fibroblasts showed increased expression of Type I collagen and transforming growth factor $\beta$ (TGF- $\beta$ ) (Hutchinson et al., 2013). Since this latter study was performed in ventricular fibroblasts it remains to be determined if similar changes occur in the atria of Type II diabetic mice. On the other hand, the notion of enhanced atrial fibrosis in association with increased expression of collagens is supported in studies of Type I diabetic Akita mice in which right and left atrial fibrosis was increased in association with enhanced atrial expression of Type I and Type III collagens (Krishnaswamy et al., 2015) (Figure 4). Interestingly, the increase in atrial fibrosis in Akita mice was preventable by chronic insulin treatment.
Hyperglycemia in Type I and Type II DM is associated with enhanced angiotensin II, TGF- $\beta$ signaling, and increased reactive-oxygen species (ROS) production (Singh et al., 2008a,b; Patel et al., 2012; Fiaschi et al., 2014). These are all wellcharacterized pro-fibrotic signaling molecules that enhance collagen synthesis and secretion by cardiac fibroblasts suggesting that these factors may contribute to atrial fibrosis and enhanced susceptibility to AF in DM. Consistent with this, angiotensinconverting enzyme inhibitors have been shown to reduce collagen and TGF- $\beta$ levels in both Type I DM (Singh et al., 2008b) and Type II DM (Toblli et al., 2005). Angiotensin II is well-known to induce cardiac fibrosis and the findings mentioned above are consistent with the hypothesis that Angiotensin II is an important mediator of atrial fibrosis in DM.

Additionally, elevations in blood glucose levels stimulate the production of advanced glycation-end products (AGEs), which can enhance interstitial fibrosis by forming crosslinks between collagen and laminin (Russo and Frangogiannis, 2016). AGEs function by activating their receptors (RAGEs) located on the surface of cardiac fibroblasts, thereby upregulating connective tissue growth factor and stimulating fibroblast proliferation (Kato 


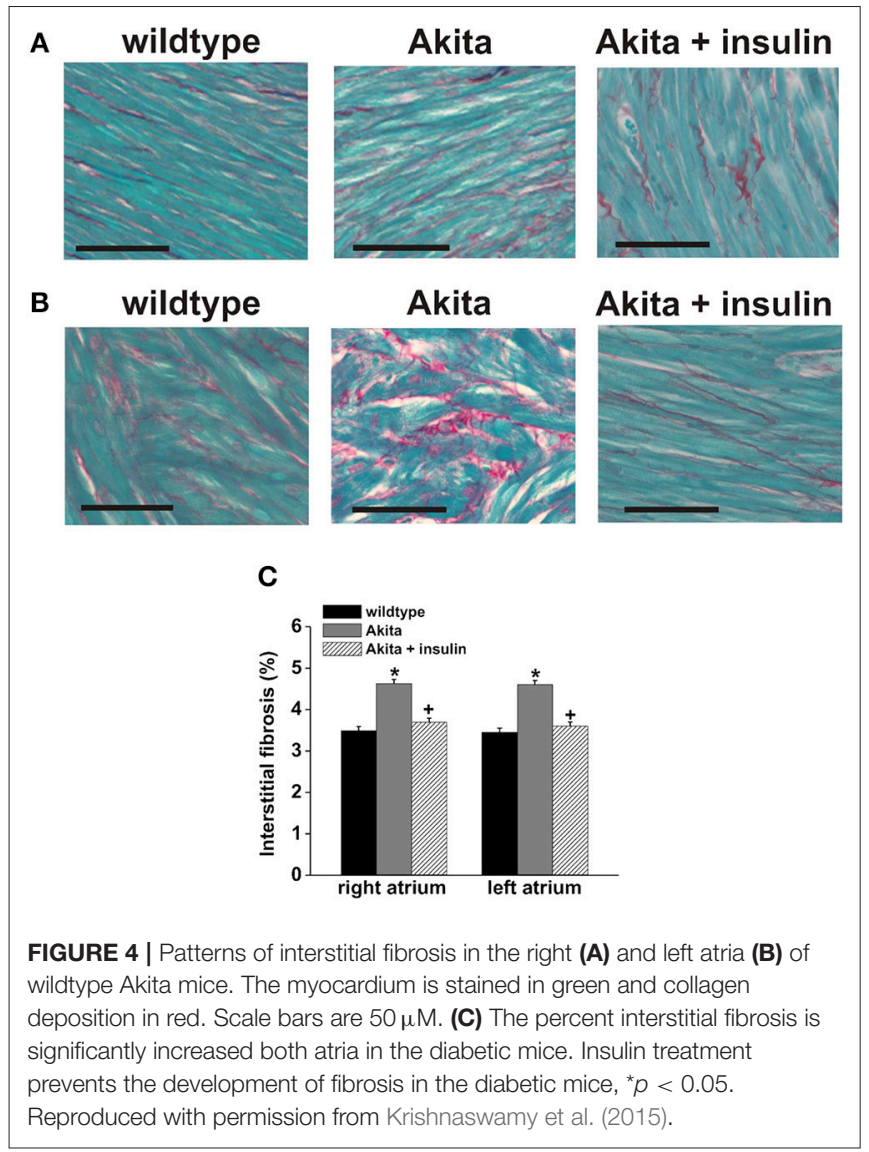

et al., 2008). This is referred to as the AGE-RAGE system and is thought to be another important mediator of profibrotic signaling in the atria in DM.

Atrial fibrosis, and hence the substrate for AF, may also be affected by adipokines-important signaling molecules than can be produced in the epicardial fat layer on the surface of the heart and which can act in a paracrine manner. Adipokines such as leptin and adiponectin have been implicated in atrial fibrosis. Leptin levels are elevated in obesity and DM (Karmazyn et al., 2008) and it has been demonstrated that leptin plays an important role in the development of atrial fibrosis. Specifically, the development of atrial fibrosis and the increased susceptibility to AF in response to Angiotensin II treatment increased leptin and was attenuated in leptin deficient ob/ob mice. Angiotensin II was shown to increase leptin expression in wildtype atrial fibroblasts and the addition of leptin increased TGF- $\beta$ signaling (Fukui et al., 2013). A subsequent study demonstrated that a high fat diet in wildtype mice resulted in hyperleptinemia as well as high susceptibility to AF in association with increased left atrial interstitial fibrosis and that these effects were attenuated in leptin deficient ob/ob mice (Fukui et al., 2017). The role of adiponectin in $\mathrm{AF}$ associated with diabetes is much less clear. Adiponectin has insulin sensitizing properties and anti-inflammatory properties and the levels of adiponectin decrease with increasing adiposity (Karmazyn et al., 2008). Interestingly, higher circulating levels of adiponectin have been associated with increased risk of AF
(Macheret et al., 2015). The basis for this observation is unclear and more work is needed to understand the role of adiponectin in cardiovascular diseases including diabetes and its links to AF.

\section{Adipose Tissue}

Type II DM presents a unique challenge in understanding the pathogenesis of AF because it typically coincides with obesity. Complications that arise from either condition are not mutually exclusive. Obesity is associated with increased thickness of epicardial adipose tissue (the fat that lies directly adjacent to the epicardium underneath the pericardium), which can have profound consequences on atrial electrophysiology and promote arrhythmogenesis (Abed et al., 2013; Mahajan et al., 2015; Evin et al., 2016). Indeed, increases in epicardial adipose tissue have been found to associate with adverse left atrial remodeling and increased incidence of AF, supporting the idea that epicardial adipose tissue could play an important role in the pathophysiology of AF (Sanghai et al., 2018). Coinciding with the increased epicardial adipose tissue volume, fatty infiltration of the atrial epicardium is also increased (Mahajan et al., 2015). Epicardial adipose tissue infiltration is associated with increased risk of AF due in part to pathological remodeling of epicardial adipose tissue itself whereby organized adipose tissue is replaced with fibro-fatty infiltrates (i.e., lipomatous metaplasia) leading to interstitial fibrosis. Indeed, an ovine model of induced AF revealed increased adipose tissue volume in the left and right atria as well as fibrosis of fatty infiltrates in comparison to their non-AF-induced counterparts (Haemers et al., 2017). Ultimately, this process impairs conduction velocity as well as homogeneity. Much like collagen fibers, fatty tissue is neither conductive nor contractile and can create physical barriers between cardiomyocytes, limiting both electro- and mechanotransduction. Additionally, the presence of these lipid deposits within the myocardium could potentially create re-entry points, further potentiating $\mathrm{AF}$ substrate development. It is not known if diabetes exacerbates this pathological process. Finally, epicardial adipose tissue is well-known to produce and release a number of compounds (including cytokines/adipokines, as discussed above) that could act in a paracrine fashion in the atria, thereby influencing atrial remodeling and arrhythmogenesis (Hatem and Sanders, 2014; Nagy et al., 2017). The role of paracrine effects of epicardial adipose tissue in the pathogenesis of $\mathrm{AF}$ is an important area for ongoing study.

\section{Electrical Remodeling Ion Channels}

Electrical remodeling in DM can also involve alterations in atrial action potential morphology due to changes in a number of ionic currents. Prolongation of the atrial action potential duration has been reported in rabbit and mouse models of Type I DM (Yi et al., 2015; Fu et al., 2016). Similar alterations have been described in the left atrium of Type II diabetic rats (Li et al., 2016). Although incompletely understood, alterations in atrial action potential morphology may involve $\mathrm{Na}^{+}$and $\mathrm{K}^{+}$channels, as well as $\mathrm{Ca}^{2+}$ homeostasis.

Evidence suggest that the $\mathrm{Na}^{+}$current $\left(\mathrm{I}_{\mathrm{Na}}\right)$ is reduced in the atria of Type I diabetic rabbits (Liu et al., 2017). In contrast, a 
study in Type II diabetic rats reported no differences in atrial $\mathrm{I}_{\mathrm{Na}}$ (Li et al., 2016). Accordingly, more work is needed to determine how atrial $\mathrm{I}_{\mathrm{Na}}$ is affected in type I and Type II DM. This is of importance as changes in $\mathrm{I}_{\mathrm{Na}}$ amplitude affect atrial action potential upstroke velocity and hence conduction velocity. In this way, $\mathrm{I}_{\mathrm{Na}}$ is an important determinant of the substrate for re-entry. Another aspect of $\mathrm{I}_{\mathrm{Na}}$ that may be important is the late $\mathrm{I}_{\mathrm{Na}}\left(\mathrm{I}_{\mathrm{Na}, \mathrm{L}}\right)$ that can affect arrhythmogenesis by modulating action potential duration and the occurrence of EADs (Sicouri et al., 2013). $\mathrm{I}_{\mathrm{Na}, \mathrm{L}}$ has been shown to be increased in ventricular myocytes in Akita and $\mathrm{db} / \mathrm{db}$ mice (Lu et al., 2013); however, it is presently unknown if this is also the case in the atria.

$\mathrm{K}^{+}$currents play an essential role in action potential repolarization thereby controlling action potential duration and susceptibility to triggered activity (EADs). Several studies have identified changes in $\mathrm{K}^{+}$currents in the atria in DM. For example, Type I diabetic (Akita) mice have been shown to have a reduction in atrial acetylcholine-activated $\mathrm{K}^{+}$current $\left(\mathrm{I}_{\mathrm{KACh}}\right)$ in association with reduced expression of GIRK1 and GIRK4 (Park et al., 2009; Zhang et al., 2014). These alterations in $\mathrm{I}_{\mathrm{KACh}}$ and GIRK expression were associated with altered insulin signaling through glycogen synthase kinase 3 and altered transcriptional regulation by sterol regulatory element binding protein 1 . A reduction in $\mathrm{I}_{\mathrm{KACh}}$ could affect atrial action potential duration and arrhythmogenesis; however, the links between $\mathrm{I}_{\mathrm{KACh}}$ and AF have not been explored in detail.

Separate studies have shown that expression of several other $\mathrm{K}^{+}$channels is altered in DM. Specifically, expression of Kv4.2/4.3, the channels that produce the transient outward $\mathrm{K}^{+}$ current $\left(\mathrm{I}_{\mathrm{to}}\right)$, is reduced in atrial myocytes in mouse models of diet induced obesity and Type II DM. The mechanism for this reduction is unclear, but may involve impaired insulin signaling as Kv4.2 expression has also been shown to be decreased in a cardiac specific insulin receptor knockout mouse (Lopez-Izquierdo et al., 2014).

Other investigations have demonstrated that Type I diabetic mice (STZ treatment) display reduced expression of small conductance $\mathrm{Ca}^{2+}$-activated $\mathrm{K}^{+}$channels (SK), including SK2 and SK3 (Yi et al., 2015). These changes in the expression of SK channels occurred in association with increased oxidative stress. Consistent with these animal studies, expression of SK channels (SK1, 2, and 3) was found to be reduced in the atria of human patients with chronic AF (Yu et al., 2012; Skibsbye et al., 2014). Additional studies are needed to better understand the links between SK channel function, diabetes, and AF.

\section{Gap Junctions}

Gap junctions play an integral role in cell to cell communication and electrical conduction. These gap junctions are composed of connexin $(\mathrm{Cx})$ proteins, with $\mathrm{Cx} 40$ and $\mathrm{Cx} 43$ being the predominant isoforms in the atrial myocardium. While data are limited, there is evidence of changes in $\mathrm{Cx}$ expression and function in the atria in DM. For example, it has been shown that Cx40 expression is reduced in the atria in a rat model of Type I DM. Consistent with this alteration in Cx40, optical mapping experiments showed that conduction velocity in the atria was reduced and conduction patterns lacked homogeneity (Figure 5)

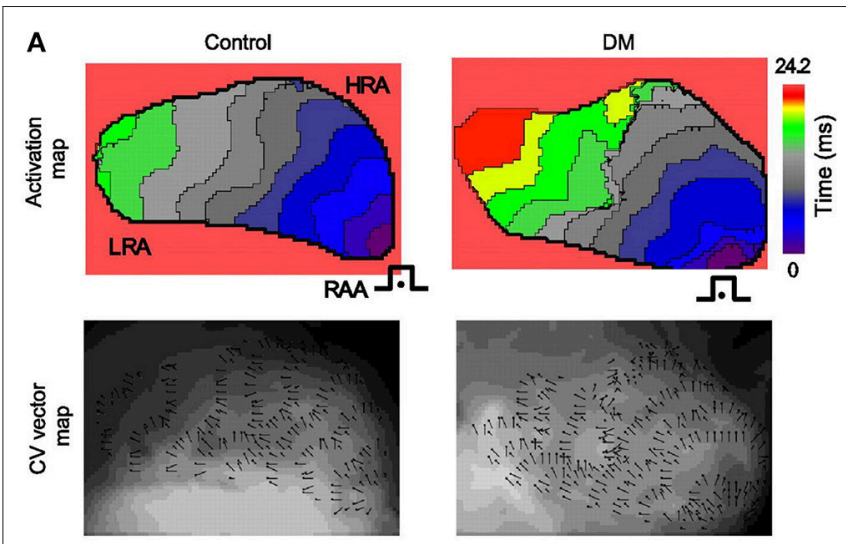

B

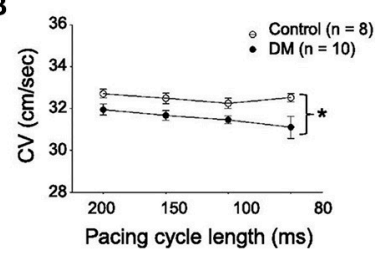

FIGURE 5 | (A) representative activation maps (top) and conduction velocity (CV) vector maps (bottom) from control (left) and DM (right) rats. The isochrones on the activation maps are drawn at $2.2 \mathrm{~ms}$ intervals. Pacing is $(\bullet)$ from the right atrial appendage (RAA) at a cycle length of $200 \mathrm{~ms}$. The color scale bar ranged from 0 to $24.2 \mathrm{~ms}$. Isochronal crowding is evident within right atrium (RA) of DM rats. The CV vector map and the direction and magnitude of focal CV vectors varies widely within RA from DM rats. (B) Mean CVs at different pacing cycle lengths in control $(n=8)$ and $\mathrm{DM}(n=10)$ rats. ${ }^{*} P<0.01$ vs. control. Reproduced with permission from Watanabe et al. (2012).

(Watanabe et al., 2012). These observations are in agreement with studies showing increased atrial arrhythmogenesis in Cx40 deficient mice (Hagendorff et al., 1999).

Cx43 expression in the atria does not appear to be changed in the setting of Type I or Type II DM. However, there is evidence that its subcelluar distribution is altered. For example, in Type II diabetic rats, $\mathrm{Cx} 43$ expression was not changed, but these animals displayed increased lateralization of $\mathrm{Cx} 43$ in the left atrium (Li et al., 2016). Lateralization of connexins would increase conduction heterogeneity because fewer $\mathrm{Cx} 43$ comprised gap junctions would be localized to the intercalated disks. Consistent with this hypothesis, lateralization of $\mathrm{Cx} 43$ and altered conduction has also been demonstrated in the ventricles of rats with Type I DM (Nygren et al., 2007).

\section{Translational Considerations: Glycemic Control and AF}

A few clinical studies have attempted to elucidate association between markers of glycemic control and AF. An analysis of the Framingham Heart Study Offspring cohort followed for $\leq 10$ years reported no association between insulin resistance and incident AF (Fontes et al., 2012). In contrast, in the Malmo Preventive Project, higher levels of fasting plasma insulin were associated with a lower risk of AF (Johnson et al., 2014). This relationship was significant only in the male cohort although the proportion of women 
included in this study was lower (33\%). Furthermore, the association was weaker in subjects with elevated fasting glucose. Spontaneous hypoglycemia has been reported to be significantly associated with the development of AF in Type II DM (Ko et al., 2018). However, the mechanism underlying this relationship is unknown. Our experimental data in Type I DM demonstrates that acute and chronic insulin therapy prevents the downregulation of the sodium current and reduces the inducibility of AF. This effect is mediated, in part, via phosphatidylinositol 3,4,5-triphosphate (Bohne et al., 2018). We have also shown that insulin treatment in this model also reduces the development of atrial fibrosis. Together these data suggest that insulin mitigates, at least in part, the development of the substrate for atrial reentry (Krishnaswamy et al., 2015).

A Danish nationwide cohort study investigated the role of thiazlidinediones compared to other second line diabetes therapy in 108,624 patients with DM and without prior AF who were treated with metformin or sulfonylurea as first line drug therapy (Pallisgaard et al., 2017). Thiazlidinediones compared to other second line diabetes therapy significantly reduced the risk of AF (HR 0.76, 95\% CI 0.57-1.00). A subsequent meta-analysis was undertaken including three randomized clinical trials and four observational studies of 130,854 diabetic patients (Zhang et al., 2017). Overall, thiazlidinediones were associated with a $27 \%$ lower risk of developing AF compared to controls. Pioglitazone was reported to have a more beneficial effect for AF prevention compared to rosiglitazone. In an experimental model of Type II DM, rosiglitazone attenuated the atrial structural remodeling and vulnerability to AF (Liu et al., 2014). A more recent study, the Bypass Angioplasty Revascularization Investigation 2 Diabetes trial, randomized patients with Type II $\mathrm{DM}$ to insulin sensitization therapy vs. insulin provision therapy. The incidence of AF was similar in in both patient groups (HR 0.91, 95\% CI 0.60-1.38). Furthermore, the incidence rate of $\mathrm{AF}$ in those treated with thiazolidinediones was similar in those not treated with thiazolidinediones. Together these data suggest that glycemic control prevents adverse atrial remodeling and propensity to AF in DM. However, the current data do not support a unique drug specific effect for AF prevention.

\section{Vascular Disease in DM}

$\mathrm{DM}$ is associated with an accelerated development and increased risk of atherosclerosis. However, DM has been reported to be an independent risk factor for AF in most observational studies (Xiong et al., 2018). Nevertheless, coronary microvascular dysfunction characterized by reduced coronary flow reserve and endothelial dysfunction are associated with DM and precede the development of overt cardiac disease (Kibel et al., 2017). These abnormalities may develop as a consequence of metabolic, hormonal, hemodynamic, neural, and other factors associated with DM. Abnormalities of endothelial function may precede the development of AF (Shaikh et al., 2016). However, whether the presence of microvascular dysfunction directly influences the substrate for AF requires more experimental and clinical investigation.

\section{Autonomic Dysfunction and AF}

Abnormalities of the autonomic nervous system may play a role in the pathogenesis of AF. Autonomic neuropathy is a frequent complication associated with DM although data on the association of this complication with AF is limited. A strong relationship between autonomic dysfunction measured using heart rate variability as the marker of autonomic function and silent AF has been reported in patients with type 2 DM (Rizzo et al., 2015). Heart rate recovery, another index of autonomic function, has also been reported to be predictive of a risk for $\mathrm{AF}$ in type $2 \mathrm{DM}$ independent of left atrial volume index and other clinical factors including hypertension and coronary artery disease suggesting a role for autonomic dysfunction in the pathogenesis of AF in DM (Negishi et al., 2013). The underlying cellular mechanisms have not been extensively studied and require further investigation.

\section{Catheter Ablation and AF}

Catheter ablation is an established therapy for symptomatic patients with AF. Some (Anselmino et al., 2015; Bunch et al., 2015; Akkaya et al., 2018; Budzianowski et al., 2018) but not all (Bogossian et al., 2016; Winkle et al., 2016) studies have suggested that recurrence rates in patients with DM undergoing catheter ablation are higher than in non-diabetic patients. However, in a meta-analysis of 15 studies including 1,464 patients with $\mathrm{DM}$, long term maintenance of sinus rhythm following a redo procedure was similar to rates reported among the general population undergoing catheter ablation. In this meta-analysis, higher body mass index and higher glycated hemoglobin levels were associated with higher AF recurrence rates suggesting a role for the metabolic abnormalities in DM in promoting arrhythmogenesis (Anselmino et al., 2015).

\section{Role of Computational Modeling}

Computational biology and modeling can be powerful approaches for studying the mechanistic basis for cardiac arrhythmias, including in DM. Whenever possible, these approaches should be considered in order to complement clinical and basis science research as well as to generate new hypotheses that can then be tested in established models and in patients. Computational approaches have proven to be a valuable and important approach in assessing the links between $\mathrm{DM}$ and AF. In this regard, a recent study used a machine learning approach to automatically select studies for inclusion in an updated meta-analysis of the association between DM and new onset AF (Xiong et al., 2018). This study showed that machine learning could accurately and objectively select studies for inclusion in meta-analyses, which is important given that the exponential growth in numbers of publications makes manual selection increasingly challenging. This machine learning study demonstrates that $\mathrm{DM}$ is a strong, independent risk factor $\mathrm{AF}$ (Xiong et al., 2018).

Computational modeling and simulations based on mechanistic insights into AF triggers and substrate derived from both experimental and clinical studies may also facilitate the development of safer and more effective therapeutic interventions (Boyle et al., 2016; Grandi and Maleckar, 2016). 
In this regard, advanced analysis of the ECG and integration of detailed clinical data including cardiac imaging, biomarkers and genomics may facilitate the development of more precision directed medical therapy (Gillis et al., 2013; Boyle et al., 2016). Future studies are required to evaluate the role of personalized computational models for individualizing therapeutic strategies for the AF patient with DM.

\section{Future Research Directions}

Experimental data demonstrate that significant atrial electrical, structural and autonomic remodeling occur in both Type I and Type II DM and increase the vulnerability to AF. Whether the insulin resistance in type II DM activates unique intracellular signaling pathways independent of obesity requires further investigation. Future studies are also required to investigate the inter-relationships between obesity, hypertension, DM, obstructive sleep apnea, and other factors associated with the metabolic syndrome including systemic inflammation

\section{REFERENCES}

Abed, H. S., Samuel, C. S., Lau, D. H., Kelly, D. J., Royce, S. G., Alasady, M., et al. (2013). Obesity results in progressive atrial structural and electrical remodeling: implications for atrial fibrillation. Heart Rhythm 10, 90-100. doi: 10.1016/j.hrthm.2012.08.043

Akkaya, E., Berkowitsch, A., Zaltsberg, S., Greiss, H., Hamm, C. W., Sperzel, J., et al. (2018). Five-year outcome and predictors of success after second-generation cryoballoon ablation for treatment of symptomatic atrial fibrillation. Int. J. Cardiol. 266, 106-111. doi: 10.1016/j.ijcard.2018.03.069

Anselmino, M., Matta, M., D’ascenzo, F., Pappone, C., Santinelli, V., Bunch, T. J., et al. (2015). Catheter ablation of atrial fibrillation in patients with diabetes mellitus: a systematic review and meta-analysis. Europace 17, 1518-1525. doi: 10.1093/europace/euv214

Arias-Mutis, O. J., Marrachelli, V. G., Ruiz-Sauri, A., Alberola, A., Morales, J. M., Such-Miquel, L., et al. (2017). Development and characterization of an experimental model of diet-induced metabolic syndrome in rabbit. PLOS ONE 12:e0178315. doi: 10.1371/journal.pone.0178315

Benjamin, E. J., Levy, D., Vaziri, S. M., D’agostino, R. B., Belanger, A. J., and Wolf, P. A. (1994). Independent risk factors for atrial fibrillation in a population-based cohort. The Framingham Heart Study. JAMA 271, 840-844. doi: 10.1001/jama.1994.03510350050036

Bogossian, H., Frommeyer, G., Brachmann, J., Lewalter, T., Hoffmann, E., Kuck, K. H., et al. (2016). Catheter ablation of atrial fibrillation and atrial flutter in patients with diabetes mellitus: who benefits and who does not? Data from the German ablation registry. Int. J. Cardiol. 214, 25-30. doi: 10.1016/j.ijcard.2016.03.069

Bohne, L. J., Polina, I., Jansen, H. J., Li, T., Krishnaswamy, P., Egom, E. E., et al. (2018). Distinct effects of acute and chronic insulin treatment on atrial electrophysiology and susceptibility to atrial fibrillation in type 1 diabetes mellitus. Heart Rhythm 15, Suppl. S7 (abstract).

Boyle, P. M., Zahid, S., and Trayanova, N. A. (2016). Towards personalized computational modelling of the fibrotic substrate for atrial arrhythmia. Europace 18, iv136-iv145. doi: 10.1093/europace/euw358

Budzianowski, J., Hiczkiewicz, J., Burchardt, P., Pieszko, K., Rzezniczak, J., Budzianowski, P., et al. (2018). Predictors of atrial fibrillation early recurrence following cryoballoon ablation of pulmonary veins using statistical assessment and machine learning algorithms. Heart Vessels 34, 352-359. doi: $10.1007 / \mathrm{s} 00380-018-1244-\mathrm{z}$

Bunch, T. J., May, H. T., Bair, T. L., Jacobs, V., Crandall, B. G., Cutler, M., et al. (2015). Five-year outcomes of catheter ablation in patients with atrial fibrillation and left ventricular systolic dysfunction. J. Cardiovasc. Electrophysiol. 26, 363-370. doi: 10.1111/jce.12602 and oxidative stress. The relationship between incident AF and glycemic control also requires further investigation. In addition, the role of computational models in directing more precision therapy for $\mathrm{AF}$ in this setting requires further study.

\section{AUTHOR CONTRIBUTIONS}

All authors listed have made a substantial, direct and intellectual contribution to the work, and approved it for publication.

\section{FUNDING}

This work was supported by operating grants from the Canadian Institutes of Health Research to RR (MOP 142486, 93718). RR holds a New Investigator Award from the Heart and Stroke Foundation of Canada. LB holds a Libin Cardiovascular Institute of Alberta Graduate Studentship.

Dahlqvist, S., Rosengren, A., Gudbjornsdottir, S., Pivodic, A., Wedel, H., Kosiborod, M., et al. (2017). Risk of atrial fibrillation in people with type 1 diabetes compared with matched controls from the general population: a prospective case-control study. Lancet Diabetes Endocrinol. 5, 799-807. doi: 10.1016/S2213-8587(17)30262-0

Evin, M., Broadhouse, K. M., Callaghan, F. M., Mcgrath, R. T., Glastras, S., Kozor, R., et al. (2016). Impact of obesity and epicardial fat on early left atrial dysfunction assessed by cardiac MRI strain analysis. Cardiovasc. Diabetol. 15:164. doi: 10.1186/s12933-016-0481-7

Fiaschi, T., Magherini, F., Gamberi, T., Lucchese, G., Faggian, G., Modesti, A., et al. (2014). Hyperglycemia and angiotensin II cooperate to enhance collagen I deposition by cardiac fibroblasts through a ROSSTAT3-dependent mechanism. Biochim. Biophys. Acta 1843, 2603-2610. doi: 10.1016/j.bbamcr.2014.07.009

Fontes, J. D., Lyass, A., Massaro, J. M., Rienstra, M., Dallmeier, D., Schnabel, R. B., et al. (2012). Insulin resistance and atrial fibrillation (from the Framingham Heart Study). Am. J. Cardiol. 109, 87-90. doi: 10.1016/j.amjcard.2011.08.008

Fu, H., Li, G., Liu, C., Li, J., Cheng, L., Yang, W., et al. (2016). Probucol prevents atrial ion channel remodeling in an alloxan-induced diabetes rabbit model. Oncotarget 7, 83850-83858. doi: 10.18632/oncotarget.13339

Fu, H., Li, G., Liu, C., Li, J., Wang, X., Cheng, L., et al. (2015). Probucol prevents atrial remodeling by inhibiting oxidative stress and TNFalpha/NF-kappaB/TGF-beta signal transduction pathway in alloxan-induced diabetic rabbits. J. Cardiovasc. Electrophysiol. 26, 211-222. doi: 10.1111/ jce. 12540

Fukui, A., Ikebe-Ebata, Y., Kondo, H., Saito, S., Aoki, K., Fukunaga, N., et al. (2017). Hyperleptinemia exacerbates high-fat diet-mediated atrial fibrosis and fibrillation. J. Cardiovasc. Electrophysiol. 28, 702-710. doi: 10.1111/ jce. 13200

Fukui, A., Takahashi, N., Nakada, C., Masaki, T., Kume, O., Shinohara, T., et al. (2013). Role of leptin signaling in the pathogenesis of angiotensin II-mediated atrial fibrosis and fibrillation. Circ. Arrhythm. Electrophysiol. 6, 402-409. doi: 10.1161/CIRCEP.111.000104

Gillis, A. M., Krahn, A. D., Skanes, A. C., and Nattel, S. (2013). Management of atrial fibrillation in the year 2033: new concepts, tools, and applications leading to personalized medicine. Can. J. Cardiol. 29, 1141-1146. doi: 10.1016/j.cjca.2013.07.006

Grandi, E., and Maleckar, M. M. (2016). Anti-arrhythmic strategies for atrial fibrillation: the role of computational modeling in discovery, development, and optimization. Pharmacol. Ther. 168, 126-142. doi: 10.1016/j.pharmthera.2016.09.012

Haemers, P., Hamdi, H., Guedj, K., Suffee, N., Farahmand, P., Popovic, N., et al. (2017). Atrial fibrillation is associated with the fibrotic remodelling of adipose 
tissue in the subepicardium of human and sheep atria. Eur. Heart J. 38, 53-61. doi: 10.1093/eurheartj/ehv625

Hagendorff, A., Schumacher, B., Kirchhoff, S., Luderitz, B., and Willecke, K. (1999). Conduction disturbances and increased atrial vulnerability in Connexin40deficient mice analyzed by transesophageal stimulation. Circulation 99, 1508-1515. doi: 10.1161/01.CIR.99.11.1508

Hatem, S. N., and Sanders, P. (2014). Epicardial adipose tissue and atrial fibrillation. Cardiovasc. Res. 102, 205-213. doi: 10.1093/cvr/cvu045

Hayami, N., Sekiguchi, A., Iwasaki, Y. K., Murakawa, Y., and Yamashita, T. (2016). No additional effect of DPP-4 inhibitor on preventing atrial fibrosis in streptozotocin-induced diabetic rat as compared with sulfonylurea. Int. Heart J. 57, 336-340. doi: 10.1536/ihj.15-266

Heijman, J., Guichard, J. B., Dobrev, D., and Nattel, S. (2018). Translational challenges in atrial fibrillation. Circ. Res. 122, 752-773. doi: 10.1161/CIRCRESAHA.117.311081

Heijman, J., Voigt, N., Nattel, S., and Dobrev, D. (2014). Cellular and molecular electrophysiology of atrial fibrillation initiation, maintenance, and progression. Circ. Res. 114, 1483-1499. doi: 10.1161/CIRCRESAHA.114. 302226

Hohl, M., Lau, D. H., Muller, A., Elliott, A. D., Linz, B., Mahajan, R., et al. (2017). Concomitant obesity and metabolic syndrome add to the atrial arrhythmogenic phenotype in male hypertensive rats. J. Am. Heart Assoc. 6:e06717. doi: 10.1161/JAHA.117.006717

Hsueh, W., Abel, E. D., Breslow, J. L., Maeda, N., Davis, R. C., Fisher, E. A., et al. (2007). Recipes for creating animal models of diabetic cardiovascular disease. Circ. Res. 100, 1415-1427. doi: 10.1161/01.RES.0000266449.37396.1f

Hutchinson, K. R., Lord, C. K., West, T. A., and Stewart, J. A. Jr. (2013). Cardiac fibroblast-dependent extracellular matrix accumulation is associated with diastolic stiffness in type 2 diabetes. PLOS ONE 8:e72080. doi: 10.1371/journal.pone.0072080

Huxley, R. R., Alonso, A., Lopez, F. L., Filion, K. B., Agarwal, S. K., Loehr, L. R., et al. (2012). Type 2 diabetes, glucose homeostasis and incident atrial fibrillation: the Atherosclerosis Risk in Communities study. Heart 98, 133-138. doi: 10.1136/heartjnl-2011-300503

Huxley, R. R., Filion, K. B., Konety, S., and Alonso, A. (2011). Meta-analysis of cohort and case-control studies of type 2 diabetes mellitus and risk of atrial fibrillation. Am. J. Cardiol. 108, 56-62. doi: 10.1016/j.amjcard. 2011.03.004

Johnson, L. S., Juhlin, T., Engstrom, G., and Nilsson, P. M. (2014). Low fasting plasma insulin is associated atrial fibrillation in men from a cohort study-the Malmo preventive project. BMC Cardiovasc. Disord. 14:107. doi: 10.1186/1471-2261-14-107

Karmazyn, M., Purdham, D. M., Rajapurohitam, V., and Zeidan, A. (2008). Signalling mechanisms underlying the metabolic and other effects of adipokines on the heart. Cardiovasc. Res. 79, 279-286. doi: 10.1093/cvr/cvn115

Kato, T., Yamashita, T., Sekiguchi, A., Tsuneda, T., Sagara, K., Takamura, M., et al. (2008). AGEs-RAGE system mediates atrial structural remodeling in the diabetic rat. J. Cardiovasc. Electrophysiol. 19, 415-420. doi: 10.1111/j.1540-8167.2007.01037.x

Kibel, A., Selthofer-Relatic, K., Drenjancevic, I., Bacun, T., Bosnjak, I., Kibel, D., et al. (2017). Coronary microvascular dysfunction in diabetes mellitus. J. Int. Med. Res. 45, 1901-1929. doi: 10.1177/0300060516675504

King, A. J. (2012). The use of animal models in diabetes research. Br. J. Pharmacol. 166, 877-894. doi: 10.1111/j.1476-5381.2012.01911.x

Ko, S. H., Park, Y. M., Yun, J. S., Cha, S. A., Choi, E. K., Han, K., et al. (2018). Severe hypoglycemia is a risk factor for atrial fibrillation in type 2 diabetes mellitus: nationwide population-based cohort study. J. Diabetes Complicat. 32, 157-163. doi: 10.1016/j.jdiacomp.2017.09.009

Krahn, A. D., Manfreda, J., Tate, R. B., Mathewson, F. A., and Cuddy, T. E. (1995). The natural history of atrial fibrillation: incidence, risk factors, and prognosis in the Manitoba Follow-Up Study. Am. J. Med. 98, 476-484. doi: 10.1016/S0002-9343(99)80348-9

Krishnaswamy, P. S., Egom, E. E., Moghtadaei, M., Jansen, H. J., Azer, J., Bogachev, O., et al. (2015). Altered parasympathetic nervous system regulation of the sinoatrial node in Akita diabetic mice. J. Mol. Cell. Cardiol. 82, 125-135. doi: 10.1016/j.yjmcc.2015.02.024

Lamberts, R. R., Lingam, S. J., Wang, H. Y., Bollen, I. A., Hughes, G., Galvin, I. F., et al. (2014). Impaired relaxation despite upregulated calcium-handling protein atrial myocardium from type 2 diabetic patients with preserved ejection fraction. Cardiovasc. Diabetol. 13:72. doi: 10.1186/1475-2840-13-72

Li, B., Pan, Y., and Li, X. (2016). Type 2 diabetes induces prolonged P-wave duration without left atrial enlargement. J. Korean Med. Sci. 31, 525-534. doi: 10.3346/jkms.2016.31.4.525

Linz, D., Hohl, M., Dhein, S., Ruf, S., Reil, J. C., Kabiri, M., et al. (2016). Cathepsin A mediates susceptibility to atrial tachyarrhythmia and impairment of atrial emptying function in Zucker diabetic fatty rats. Cardiovasc. Res. 110, 371-380. doi: $10.1093 / \mathrm{cvr} / \mathrm{cvw} 071$

Liu, C., Liu, R., Fu, H., Li, J., Wang, X., Cheng, L., et al. (2017). Pioglitazone attenuates atrial remodeling and vulnerability to atrial fibrillation in alloxan-induced diabetic rabbits. Cardiovasc. Ther. 35:e12284. doi: 10.1111/1755-5922.12284

Liu, T., Zhao, H., Li, J., Korantzopoulos, P., and Li, G. (2014). Rosiglitazone attenuates atrial structural remodeling and atrial fibrillation promotion in alloxan-induced diabetic rabbits. Cardiovasc. Ther. 32, 178-183. doi: 10.1111/1755-5922.12079

Lopez-Izquierdo, A., Pereira, R. O., Wende, A. R., Punske, B. B., Abel, E. D., and Tristani-Firouzi, M. (2014). The absence of insulin signaling in the heart induces changes in potassium channel expression and ventricular repolarization. Am. J. Physiol. Heart Circ. Physiol. 306, H747-H754. doi: 10.1152/ajpheart.00849.2013

Lu, Z., Jiang, Y. P., Wu, C. Y., Ballou, L. M., Liu, S., Carpenter, E. S., et al. (2013). Increased persistent sodium current due to decreased PI3K signaling contributes to QT prolongation in the diabetic heart. Diabetes 62, 4257-4265. doi: $10.2337 / \mathrm{db} 13-0420$

Macheret, F., Bartz, T. M., Djousse, L., Ix, J. H., Mukamal, K. J., Zieman, S. J., et al. (2015). Higher circulating adiponectin levels are associated with increased risk of atrial fibrillation in older adults. Heart 101, 1368-1374. doi: 10.1136/heartjnl-2014-307015

Mahajan, R., Lau, D. H., Brooks, A. G., Shipp, N. J., Manavis, J., Wood, J. P., et al. (2015). Electrophysiological, electroanatomical, and structural remodeling of the atria as consequences of sustained obesity. J. Am. Coll. Cardiol. 66, 1-11. doi: $10.1016 /$ j.jacc.2015.04.058

Nagy, E., Jermendy, A. L., Merkely, B., and Maurovich-Horvat, P. (2017). Clinical importance of epicardial adipose tissue. Arch. Med. Sci. 13, 864-874. doi: 10.5114/aoms.2016.63259

Negishi, K., Seicean, S., Negishi, T., Yingchoncharoen, T., Aljaroudi, W., and Marwick, T. H. (2013). Relation of heart-rate recovery to new onset heart failure and atrial fibrillation in patients with diabetes mellitus and preserved ejection fraction. Am. J. Cardiol. 111, 748-753. doi: 10.1016/j.amjcard.2012.11.028

Nygren, A., Olson, M. L., Chen, K. Y., Emmett, T., Kargacin, G., and Shimoni, Y. (2007). Propagation of the cardiac impulse in the diabetic rat heart: reduced conduction reserve. J. Physiol. 580, 543-560. doi: 10.1113/jphysiol.2006.123729

Pallisgaard, J. L., Lindhardt, T. B., Staerk, L., Olesen, J. B., Torp-Pedersen, C., Hansen, M. L., et al. (2017). Thiazolidinediones are associated with a decreased risk of atrial fibrillation compared with other antidiabetic treatment: a nationwide cohort study. Eur. Heart J. Cardiovasc. Pharmacother. 3, 140-146. doi: 10.1093/ehjcvp/pvw036

Pallisgaard, J. L., Schjerning, A. M., Lindhardt, T. B., Procida, K., Hansen, M. L., Torp-Pedersen, C., et al. (2016). Risk of atrial fibrillation in diabetes mellitus: a nationwide cohort study. Eur. J. Prev. Cardiol. 23, 621-627. doi: 10.1177/2047487315599892

Park, H. J., Zhang, Y., Du, C., Welzig, C. M., Madias, C., Aronovitz, M. J., et al. (2009). Role of SREBP-1 in the development of parasympathetic dysfunction in the hearts of type 1 diabetic Akita mice. Circ. Res. 105, 287-294. doi: 10.1161/CIRCRESAHA.109.193995

Patel, V. B., Bodiga, S., Basu, R., Das, S. K., Wang, W., Wang, Z., et al. (2012). Loss of angiotensin-converting enzyme-2 exacerbates diabetic cardiovascular complications and leads to systolic and vascular dysfunction: a critical role of the angiotensin II/AT1 receptor axis. Circ. Res. 110, 1322-1335. doi: 10.1161/CIRCRESAHA.112.268029

Perez, M. V., Wang, P. J., Larson, J. C., Soliman, E. Z., Limacher, M., Rodriguez, B., et al. (2013). Risk factors for atrial fibrillation and their population burden in postmenopausal women: the Women's Health Initiative Observational Study. Heart 99, 1173-1178. doi: 10.1136/heartjnl-2013-303798

Rizzo, M. R., Sasso, F. C., Marfella, R., Siniscalchi, M., Paolisso, P., Carbonara, O., et al. (2015). Autonomic dysfunction is associated with brief episodes 
of atrial fibrillation in type 2 diabetes. J. Diabetes Complicat. 29, 88-92. doi: 10.1016/j.jdiacomp.2014.09.002

Russo, I., and Frangogiannis, N. G. (2016). Diabetes-associated cardiac fibrosis: cellular effectors, molecular mechanisms and therapeutic opportunities. J. Mol. Cell. Cardiol. 90, 84-93. doi: 10.1016/j.yjmcc.2015.12.011

Saito, S., Teshima, Y., Fukui, A., Kondo, H., Nishio, S., Nakagawa, M., et al. (2014). Glucose fluctuations increase the incidence of atrial fibrillation in diabetic rats. Cardiovasc. Res. 104, 5-14. doi: 10.1093/cvr/cvu176

Samanta, R., Pouliopoulos, J., Thiagalingam, A., and Kovoor, P. (2016). Role of adipose tissue in the pathogenesis of cardiac arrhythmias. Heart Rhythm 13, 311-320. doi: 10.1016/j.hrthm.2015.08.016

Sanghai, S. R., Sardana, M., Hansra, B., Lessard, D. M., Dahlberg, S. T., Aurigemma, G. P., et al. (2018). Indexed left atrial adipose tissue area is associated with severity of atrial fibrillation and atrial fibrillation recurrence among patients undergoing catheter ablation. Front. Cardiovasc. Med, 5:76. doi: 10.3389/fcvm.2018.00076

Schnabel, R. B., Yin, X., Gona, P., Larson, M. G., Beiser, A. S., Mcmanus, D. D., et al. (2015). 50 year trends in atrial fibrillation prevalence, incidence, risk factors, and mortality in the Framingham Heart Study: a cohort study. Lancet 386, 154-162. doi: 10.1016/S0140-6736(14)61774-8

Schoen, T., Pradhan, A. D., Albert, C. M., and Conen, D. (2012). Type 2 diabetes mellitus and risk of incident atrial fibrillation in women. J. Am. Coll. Cardiol. 60, 1421-1428. doi: 10.1016/j.jacc.2012.06.030

Schotten, U., Dobrev, D., Platonov, P. G., Kottkamp, H., and Hindricks, G. (2016). Current controversies in determining the main mechanisms of atrial fibrillation. J. Intern. Med. 279, 428-438. doi: 10.1111/joim.12492

Sedgwick, B., Riches, K., Bageghni, S. A., O'regan, D. J., Porter, K. E., and Turner, N. A. (2014). Investigating inherent functional differences between human cardiac fibroblasts cultured from nondiabetic and Type 2 diabetic donors. Cardiovasc. Pathol. 23, 204-210. doi: 10.1016/j.carpath.2014.03.004

Shaikh, A. Y., Wang, N., Yin, X., Larson, M. G., Vasan, R. S., Hamburg, N. M., et al. (2016). Relations of arterial stiffness and brachial flow-mediated dilation with new-onset atrial fibrillation: the Framingham Heart Study. Hypertension 68, 590-596. doi: 10.1161/HYPERTENSIONAHA.116.07650

Sicouri, S., Belardinelli, L., and Antzelevitch, C. (2013). Antiarrhythmic effects of the highly selective late sodium channel current blocker GS-458967. Heart Rhythm 10, 1036-1043. doi: 10.1016/j.hrthm.2013.03.023

Singh, V. P., Baker, K. M., and Kumar, R. (2008a). Activation of the intracellular renin-angiotensin system in cardiac fibroblasts by high glucose: role in extracellular matrix production. Am. J. Physiol. Heart Circ. Physiol. 294, H1675-H1684. doi: 10.1152/ajpheart.91493.2007

Singh, V. P., Le, B., Khode, R., Baker, K. M., and Kumar, R. (2008b). Intracellular angiotensin II production in diabetic rats is correlated with cardiomyocyte apoptosis, oxidative stress, and cardiac fibrosis. Diabetes 57, 3297-3306. doi: $10.2337 / \mathrm{db} 08-0805$

Skibsbye, L., Poulet, C., Diness, J. G., Bentzen, B. H., Yuan, L., Kappert, U., et al. (2014). Small-conductance calcium-activated potassium (SK) channels contribute to action potential repolarization in human atria. Cardiovasc. Res. 103, 156-167. doi: 10.1093/cvr/cvu121

Son, M. K., Lim, N. K., Cho, M. C., and Park, H. Y. (2016). Incidence and risk factors for atrial fibrillation in Korea: the national health insurance service database (2002-2010). Korean Circ. J. 46, 515-521. doi: $10.4070 / \mathrm{kcj} .2016 .46 .4 .515$
Staerk, L., Sherer, J. A., Ko, D., Benjamin, E. J., and Helm, R. H. (2017). Atrial fibrillation: epidemiology, pathophysiology, and clinical outcomes. Circ. Res. 120, 1501-1517. doi: 10.1161/CIRCRESAHA.117.309732

Toblli, J. E., Cao, G., Derosa, G., and Forcada, P. (2005). Reduced cardiac expression of plasminogen activator inhibitor 1 and transforming growth factor betal in obese Zucker rats by perindopril. Heart 91, 80-86. doi: $10.1136 /$ hrt.2003.022707

Tsao, C. W., and Vasan, R. S. (2015). The Framingham Heart Study: past, present and future. Int. J. Epidemiol. 44, 1763-1766. doi: 10.1093/ije/dyv336

Watanabe, M., Yokoshiki, H., Mitsuyama, H., Mizukami, K., Ono, T., and Tsutsui, H. (2012). Conduction and refractory disorders in the diabetic atrium. Am.J. Physiol. Heart Circ. Physiol. 303, H86-H95. doi: 10.1152/ajpheart.00010.2012

Winkle, R. A., Jarman, J. W., Mead, R. H., Engel, G., Kong, M. H., Fleming, W., et al. (2016). Predicting atrial fibrillation ablation outcome: the CAAP-AF score. Heart Rhythm 13, 2119-2125. doi: 10.1016/j.hrthm.2016.07.018

Xiong, Z., Liu, T., Tse, G., Gong, M., Gladding, P. A., Smaill, B. H., et al. (2018). A machine learning aided systematic review and meta-analysis of the relative risk of atrial fibrillation in patients with diabetes mellitus. Front. Physiol. 9:835. doi: 10.3389/fphys.2018.00835

Yi, F., Ling, T. Y., Lu, T., Wang, X. L., Li, J., Claycomb, W. C., et al. (2015). Down-regulation of the small conductance calcium-activated potassium channels in diabetic mouse atria. J. Biol. Chem. 290, 7016-7026. doi: 10.1074/jbc.M114.607952

Yu, T., Deng, C., Wu, R., Guo, H., Zheng, S., Yu, X., et al. (2012). Decreased expression of small-conductance $\mathrm{Ca} 2+$-activated $\mathrm{K}+$ channels SK1 and SK2 in human chronic atrial fibrillation. Life Sci. 90, 219-227. doi: 10.1016/j.lfs.2011.11.008

Zarzoso, M., Mironov, S., Guerrero-Serna, G., Willis, B. C., and Pandit, S. V. (2014). Ventricular remodelling in rabbits with sustained high-fat diet. Acta Physiol. 211, 36-47. doi: 10.1111/apha.12185

Zhang, Y., Welzig, C. M., Picard, K. L., Du, C., Wang, B., Pan, J. Q. et al. (2014). Glycogen synthase kinase-3beta inhibition ameliorates cardiac parasympathetic dysfunction in type 1 diabetic Akita mice. Diabetes 63 2097-2113. doi: 10.2337/db12-1459

Zhang, Z., Zhang, X., Korantzopoulos, P., Letsas, K. P., Tse, G., Gong, M., et al. (2017). Thiazolidinedione use and atrial fibrillation in diabetic patients: a meta-analysis. BMC Cardiovasc. Disord. 17:96. doi: 10.1186/s12872-0170531-4

Conflict of Interest Statement: SW-Consulting Arca Biopharma and <5,000 AG-Medtronic Inc research support.

The remaining authors declare that the research was conducted in the absence of any commercial or financial relationships that could be construed as a potential conflict of interest.

Copyright (c) 2019 Bohne, Johnson, Rose, Wilton and Gillis. This is an open-access article distributed under the terms of the Creative Commons Attribution License (CC $B Y)$. The use, distribution or reproduction in other forums is permitted, provided the original author(s) and the copyright owner(s) are credited and that the original publication in this journal is cited, in accordance with accepted academic practice. No use, distribution or reproduction is permitted which does not comply with these terms. 